\title{
Use of a New High-Speed Digital Data Acquisition System in Airborne Ice-Sounding
}

\author{
DAVID L. WRIGHT, MEMBER, IEEE, JERRY A. BRADLEY, AND STEVEN M. HODGE
}

\begin{abstract}
A high-speed digital data acquisition and signal averaging system for borehole, surface, and airborne radio-frequency geophysical measurements was designed and built by the U. S. Geological Survey. The system permits signal averaging at rates high enough to achieve significant signal-to-noise enhancement in profiling, even in airborne applications.

The first field use of the system took place in Greenland in May and June, 1987 for recording data on a 150 by $150-\mathrm{km}$ grid centered on the summit of the Greenland ice sheet. About 6000-line km were flown and recorded using the new system. The data will be used to aid in siting a proposed scientific corehole through the ice sheet.
\end{abstract}

\section{INTRODUCTION}

$\mathrm{I}^{\mathrm{N}}$ $\mathrm{N}$ certain geological media such as cold fresh-water ice, halite, and some crystalline rocks, radio-frequency electromagnetic waves can propagate with relatively low attenuation; thus, these media may be conveniently probed using radars and other systems with a designed operating frequency in the range of $1 \mathrm{MHz}$ to a few hundred $\mathrm{MHz}$, depending on the application. In attempting to maximize the sensitivity of these systems, summation averaging is often employed. For noise that is uncorrelated with the desired signal, the improvement in the signal-to-noise power ratio is proportional to the number of signals averaged when signals are added phase-coherently. For a $30-\mathrm{dB}$ improvement in the signal-to-noise ratio, 1000 waveforms must be added. There are practical limits to waveform addition, a primary one being the time required to add waveforms, particularly in profiling or borehole logging operations in which it is desired or necessary to acquire data continuously, with no stops. Time is especially limiting in airborne profiling because of the high speeds involved. For this reason we have developed a new data acquisition system (DAS) in an effort to take full advantage of recent technological advances such as fast waveform digitizers and high-speed memory chips. The DAS was designed with two primary applications in mind: Borehole radar and surface-based ice-sounding radar.

The first field use of the system, however, was in airborne ice-sounding over the Greenland ice sheet. The ice-

\footnotetext{
Manuscript received November 4, 1987; revised March 13, 1989. This work was partially based upon activities supported by the National Science Foundation under Agreement No. DPP-8518618.

D. L. Wright and J. A. Bradley are with the U.S. Geological Survey, MS 964, Box 25046, Federal Center, Denver, CO 80225.

S. M. Hodge is with the U.S. Geological Survey, University of Puget Sound, Tacoma, WA 98416.

IEEE Log Number 8929067
}

sounding radar used was a unit designed and built by the Technical University of Denmark (TUD) [1]. The new DAS was successful with that radar. About 6000 -line $\mathrm{km}$ of data obtained on an evenly spaced grid were recorded on 9-track computer tape. When the data are fully reduced and maps produced, it will be possible to recommend a suitable site for a proposed scientific corehole through the ice to bedrock [2].

\section{System Description}

The new DAS shown in block diagram in Fig. 1 was designed with maximum speed and flexibility in mind. The system is based on the CAMAC (IEEE-583) standard and may be used with any computer that has an IEEE488 General Purpose Interface Bus (GPIB). To date, the system has been used with a Hewlett-Packard 9845 and an IBM PC/AT. Commercial modules were used for the digitizer (a LeCroy TR8818A) and for the CAMAC/GPIB controller (a LeCroy 8901A), but for maximum speed in waveform addition, we designed and built our own memory and internal control boards.

The minimum performance goals for the system were to:

- Provide an analog bandwidth of $100 \mathrm{MHz}$.

- Digitize 100 Megasamples/s with 8 bits.

- Digitize from 256 to 8192 points/waveform.

- Add any number of waveforms up to $65536\left(2^{16}\right)$.

- Add 50000 waveforms/s with 256 points/waveform.

- Add 5000 waveforms/s with 8192 points/waveform.

- Transfer data without interruption of acquisition.

- Trigger external device with a 1-ns delay interval.

All of the design goals except to add 5000 waveforms/s with 8192 points / waveform were achieved. For the longest records (8192 samples) the minimum digitizing time window is $82 \mu \mathrm{s}$ and the maximum waveform addition rate is about 3000 waveforms $/ \mathrm{s}$. The acquired data points are added at a rate of 33 megasamples/s, which is within a factor of three of the digitizing rate, and more than an order of magnitude faster than the 2 megasamples/s addition rate of the fastest commercial unit known to the authors. We considered other architectures that could achieve an addition rate equal to or greater than the 100 megasamples/s digitizing rate so that waveform addition could keep up with any signal repetition rate, but decided that because the fastest advertised Static Random Access 


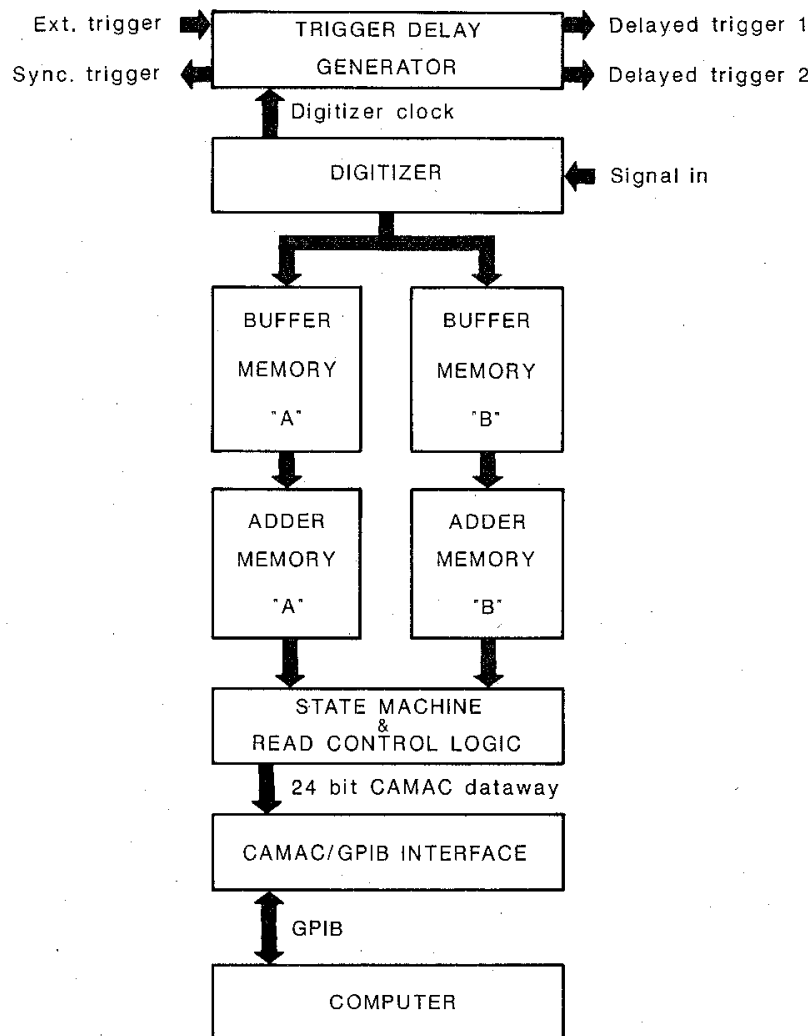

Fig. 1. The block diagram of the new data acquisition and signal averaging system. The trigger delay generator synchronizes delayed trigger outputs to the digitizer clock. Delayed pulses may be used to trigger the DAS in cases where considerable propag: : ion delay occurs between an external trigger command and arrival of $\uparrow^{\prime} f$. first data or when data points spaced more closely than $10 \mathrm{~ns}$ are requined. The output from the digitizer is stored in side " $A$ " until adder memory " $A$ " has accumulated the specified number of waveforms. Then data are stored by side " $B$ " while side " $\mathrm{A}$ " is read to the computer.

Memory (SRAM) chips were not actually available at the time the unit was built, and because considerably more complexity would be required to retain the performance goal of transferring data without interruption of acquisition, we would settle for the slower addition rate. In order to achieve transfer of data without interruption of data acquisition, we built the system with dual memories so that one side can be read while the other side is acquiring data.

Addition using a microprocessor is the common practice in commercial data acquisition systems, and we built a previous data acquisition system using a microprocessor [3]. In the new DAS, however, hard-wired arithmetic logic unit addition was chosen instead because of speed advantages. In order to achieve the highest possible speed, no normalization is performed in the DAS. The waveforms are simply directly added. With the second and fourth goals, above, we therefore require 24 bits to represent each point without overflow when accumulating the maximum 65536 waveforms with each point digitized to 8 bits. The full 24 bits are transferred to the computer over the GPIB. All 24 bits are written to mass storage, although this could be modified if desired. In high-speed profiling, such as airborne applications, the most significant bits will be empty because the number of waveforms added will be much smaller than 65536 . The number of waveforms chosen for addition is a trade-off between maximum signal-to-noise enhancement and the quantity of recorded data on the one hand versus maximum spatial data density on the other.

For devices that can be externally triggered a programmable trigger delay generator was built to allow a device (in our case, usually a short-pulse radar transmitter [4]) to be fired synchronously with the digitizer ock cr, if needed, with time delays programmable in teps as small as $1 \mathrm{~ns}$ for "interleaving" additional points titween the 10-ns interval points provided by the digitiz:. Synchronous triggering can be important for recording geophysical short-pulse radar signals where both the phase and amplitude are preserved, but it was not needed in Greenland because the TUD radar 1) was equipped with its own independent trigger source, 2) does not preserve phase in the receiver, and 3) was operated with a 250 -ns pulse length that was considerably longer than the 40-ns digitizer interval that we selected.

In operation, the software prompts the user for the digitizer clock rate, the number of samples per waveform, the number of waveforms to be added before output to the computer, and the digitizer dc offset. Data accumulation and storage occur in the " $\mathrm{A}$ " side until the programmed number of waveforms is reached. Accumulation then shifts to " $B$ " while the data in " $A$ " are read into the computer through the CAMAC/GPIB interface. The data are then displayed on the CRT and written to the mass storage unit.

The system was used in Greenland with an IBM PC/ AT computer with a Professional Graphics Controller (PGC). The mass storage unit used was a Cipher M891 9-track tape drive with cache memory. The tape controller was a unit by Overland Data. Although 9-track tape is not the most compact medium available for data storage and cannot be used at extreme temperatures, 9-track tape was selected in order to provide maximum transportability from system to system and to enable storage in a form easily archived. The tape drive is also faster than some tape cartridges, although not as fast at Vinchester disks. The measured average data transfer rate to the tape drive was $150 \mathrm{kbytes} / \mathrm{s}$. No failures of the tape system were experienced in the Greenland work.

\section{Airborne Profiling of the Greenland Ice SHEET}

\section{A. Scientific Objectives}

The primary objective of the fieldwork in Greenland was to map the bed topography in the general area of a proposed new corehole to be drilled through the ice sheet. Ice cores from a polar ice sheet can be used to extract a wide range of detailed paleoclimatic data. In central Greenland, the ice may be several hundred thousand years old at the bed, and it should be possible to make measurements on an annual basis as far back as 10000 years.

Because of increasing concern about possible anthropomorphically induced climatic changes, a major polar 
program is now developing to obtain a new, well-dated ice core and to apply many new analytical techniques that have been perfected in the years since the last ice core was drilled [ ]. The new corehole needs to be drilled in a region wher the ice flow is as simple as possible to allow reliable dativg and interpretation of the ice cores. Since the complexity of the ice flow at depth depends primarily cn the bed topography, detailed radar soundings are an essential first step in the selection of a drill site. The grid size $150 \times 150 \mathrm{~km}$ was selected to be large enough to encompass all possible drill sites based on other criteria (such as snow accumulation rates), and the grid spacing $12.5 \mathrm{~km}$ was selected based on ice flow considerations (about 3-4 times the ice thickness).

\section{B. Operations}

An LC-130 "Hercules" aircraft was used for the flights and is operated for the National Science Foundation (NSF) by the VXE-6 squadron of the U.S. Navy. It was specially modified with coaxial cables running through the wing and hard-mounting points for the four $60-\mathrm{MHz}$ TUD radar antennas. The TUD radar system has been very successful in sounding deep ice.

During operation, the data from the TUD radar was digitized and displayed in real time on the PC/AT screen. A Compaq computer was interfaced to the aircraft inertial navigation system (INS) through a navigational data acquisition system designed and built by the University of Washington [5]. Since the new DAS was untried in the field, there were three additional data acquisition systems. The first was a Honeywell "Visicorder" and camera for continuous photographic copy. When the data from both the magnetic tapes and the Visicorder are fully analyzed, comparisons can be made. The TUD radar was also equipped with film-strip recorders. Finally, a sampling oscilloscope and FM instrumentation tape recorder were the final backup system. The latter system was used as the primary data acquisition system in the first airborne sounding of Columbia Glacier, Alaska, in 1978 [6], but was not needed in Greenland. The Columbia Glacier recording system could not provide data averaging because it used signal sampling and was therefore two to three orders of magnitucis slower than the new system.

The instrumentation was housed in a hut that was designed for use on the surface in Antarctica. The hut is completely electromagnetically shielded and was used in the aircraft because of concern that the digital electronics might radiate enough RF energy that the sensitive TUD radar receiver would be effected. In practice, however, the receiver was not detectably influenced by the operation of our systems. This proved to be merciful for the DAS operators because the heat produced by our equipment made it very uncomfortable to operate with the door closed despite the presence of two vigorous ventilating fans. The hut's thermal characteristics will be more appreciated in Antarctica.

The location of the grid in central Greenland is shown in Fig. 2. The aircraft was flown each day from Thule Air

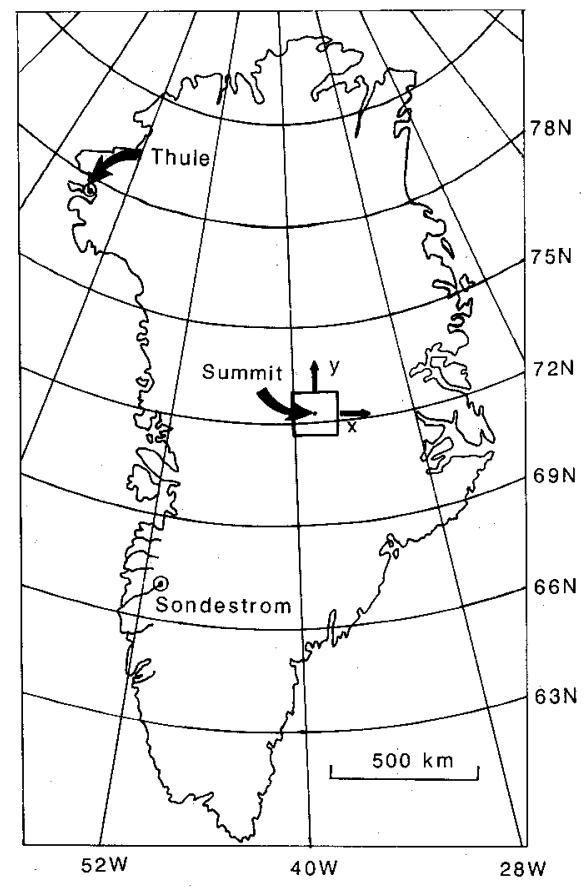

Fig. 2. The $150 \times 150-\mathrm{km}$ grid was located in central Greenland. The center of the grid was located at the summit of the Greenland ice sheet at $72^{\circ} 17^{\prime} 38.266^{\prime \prime} \mathrm{N}, 37^{\circ} 55^{\prime} 18.483^{\prime \prime} \mathrm{W}$, where the altitude at the ice surface is $3260 \mathrm{~m}$. The corners of the grid were located as follows: NW corner $(X=-75 \mathrm{~km}, Y=+75 \mathrm{~km}) 72^{\circ} 57^{\prime} 12^{\prime \prime} \mathrm{N}, 40^{\circ} 12^{\prime} 48^{\prime \prime} \mathrm{W}$; NE corner $(X=+75 \mathrm{~km}, Y=+75 \mathrm{~km}) 72^{\circ} 57^{\prime} 12^{\prime \prime} \mathrm{N}, 35^{\circ} 37^{\prime} 49^{\prime \prime} \mathrm{W}$; SE corner $(X=+75 \mathrm{~km}, Y=-75 \mathrm{~km}) 71^{\circ} 36^{\prime} 36^{\prime \prime} \mathrm{N}, 35^{\circ} 47^{\prime} 33^{\prime \prime} \mathrm{W}$; SW corner $(X=-75 \mathrm{~km}, Y=-75 \mathrm{~km}) 71^{\circ} 36^{\prime} 36^{\prime \prime} \mathrm{N}, 40^{\circ} 03^{\prime} 04^{\prime \prime} \mathrm{W}$. Data were generally obtained also in about a $15-\mathrm{km}$ wide "border zone" outside the main grid.

Base to the grid. There was usually enough time on station to fly four to six of the $150-\mathrm{km}$ lines on the grid. The grid was centered at $72^{\circ} 17^{\prime} 38.266^{\prime \prime} \mathrm{N}, 37^{\circ} 55^{\prime} 18.483^{\prime \prime}$ $\mathrm{W}$ at the summit of the Greenland ice sheet. The altitude of the ice surface at that point is $3260 \mathrm{~m}$, and the thickness of the ice is about $3000 \mathrm{~m}$.

The center of the grid was occupied at the time of our flights by a field party led by Dr. John Bolzan of the Ohio State University. The presence of the field party was important because they provided us with accurate timing marks for the calibration of the aircraft INS which became the primary navigation system. The INS was supposed to be a backup to a Global Positioning System (GPS), but for reasons that are still not clear, it was impossible to lock onto the satellites with the GPS receiver aboard the aircraft, and even a ground-based GPS receiver at Thule had difficulty achieving a lock on the satellites. This was unexpected, since tests using the same system in Greenland during the previous year and at Point Mugu, California, only one month earlier had been fully successful. After every two or three flight lines, a pass was made over the base camp to reset the INS to known coordinates. The INS drift between resets was in most cases less than $2 \mathrm{~km}$, and the grid was there flown with acceptable navigational control despite tire failure of the GPS navigation.

The TUD radar system has two output signals: The first is the direct output from the receiver. The second is de- 


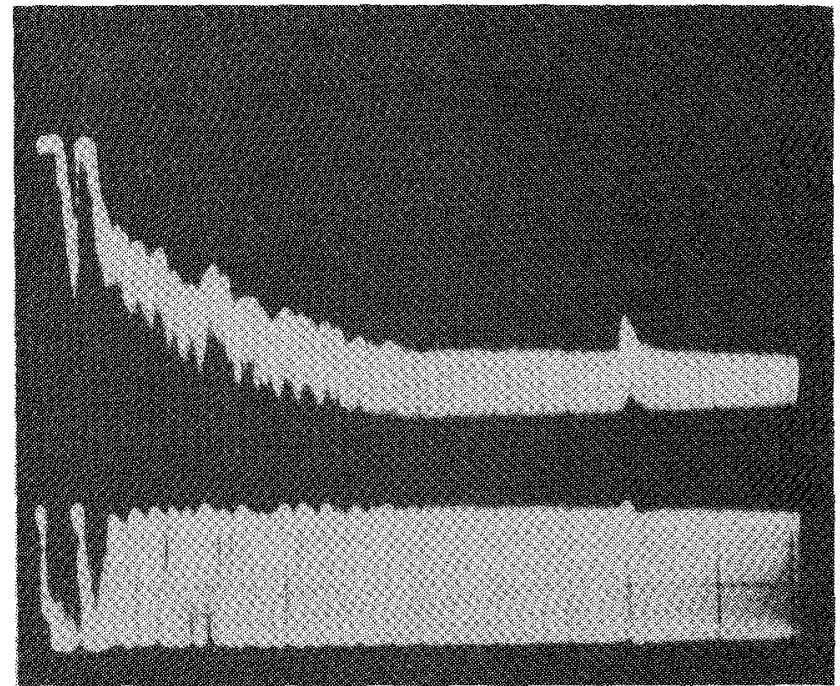

Fig. 3. The radar provides two output signals; both are displayed on a monitor oscilloscope in the radar rack. The first output, shown in the top trace, is the direct output from the radar receiver. The lower trace is a differentiated version of the direct output. For photographic recording the differentiated signal is usually superior because it requires less dynamic range in the recording medium and sharpens the image. The sweep speed is $5 \mu \mathrm{s} / \mathrm{div}$.

rived from the first by analog differentiation. Fig. 3 is a picture of the dual-trace monitor oscilloscope CRT. The upper trace is the direct amplitude output, and the lower trace is the differentiated output. Several lines were recorded first with the differentiated signal, and then using the direct signal. Further data processing will be required before a final decision is reached, but the preliminary conclusion is that it is better to record the direct signal because all the information is there, and if a differentiated signal is desired, it can be generated by numerical differentiation. Recovering the direct signal from the analog differentiated signal is not such a simple matter. Fig. 4 shows the digitized direct signal displayed on the computer monitor in "A scope" fashion. This display is available to the operator in real time as a check on the DAS operation.

When profiling, the data are displayed in raster fashion with the signal magnitude converted to a color scale with 256 displayable colors and a screen resolution of $640 \times$ 480 pixels. Each waveform is displayed on the horizontal (640 pixel) axis of the CRT. The operator can select which points are to be displayed by selecting the starting point, number of points to be displayed, and number of points skipped, if any. There are six alternative color tables included in the software and these may be toggled cyclically without interfering with data acquisition or display. It was found, as expected, that some color tables were significantly better than others in terms of the human eye's ability to discern small differences. It was also found that the operators would sometimes want to change the color table just to avoid boredom or eyestrain. The best color table for the eye does not necessarily produce the best black-and-white photographic reproduction of the color display, however. Each data word (digitized sample

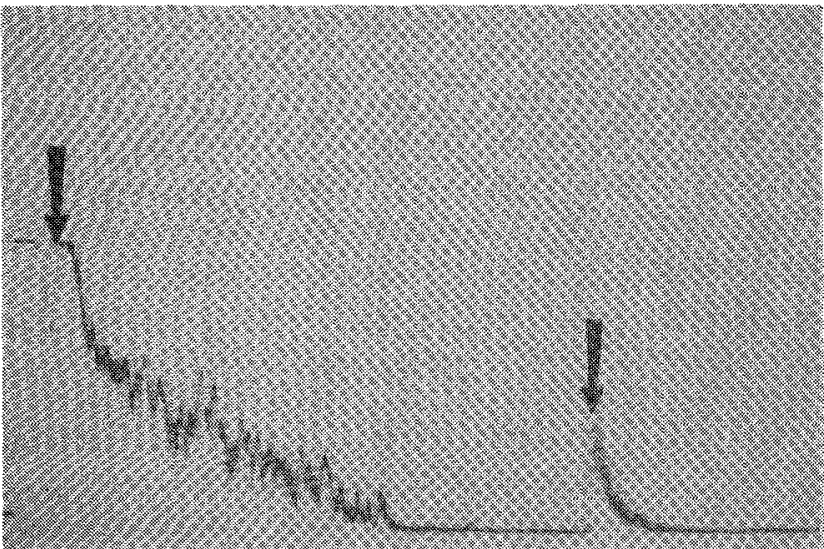

Fig. 4. The digitized direct radar receiver output displayed in "A scope" style after accumulating a number of waveforms. The surface return (left arrow) saturates the receiver for a brief period. A number of returns from internal layers in the ice are visible, then a "quiet zone,"' and finally the bottom return (right arrow). It is not clear whether the "quiet zone" indicates a nearly complete lack of internal layers deep in the ice or is at least partly due to the dynamic range limitations of the system.

point) sent from the DAS to the computer is 24 bits. The software is written so that any 8 of the 24 bits can be displayed.

A significant factor in airborne applications where reasonable spatial data density is desired is the total system cycle time. The cycle time is a function not only of the DAS parameters such as points/waveform and number of waveforms added, but also of the repetition rate of the radar and, especially for small numbers of added waveforms, the time it takes for the computer to read, process, display, and write the data to tape. The number of waveforms added before output to the computer was varied, but all of the examples shown here used 512 waveforms. The TUD radar was operated for these flights with a $12.5-\mathrm{kHz}$ repetition rate. One CRT screen is 480 lines and it took about $60 \mathrm{~s}$ to fill the screen when adding 512 waveforms. The flight speed averaged about $445 \mathrm{~km} / \mathrm{h}(240$ $\mathrm{kn})$ or $124 \mathrm{~m} / \mathrm{s}$. One full screen then represented about 7 $\mathrm{km}$, and the spatial density of recorded data was one record in about $15 \mathrm{~m}$. During the Greenland profiling each waveform was always digitized using 2048 points at a 40 -ns digitizing interval, so that each record was about $82-\mu$ s long, being sufficient to record the bottom return in the deepest part of the Greenland ice sheet. The time required to add 2048 points in the DAS, $62 \mu \mathrm{s}$, plus the $82-\mu$ s digitizing window resulted in a period, $144 \mu \mathrm{s}$, that was longer than the period, $80 \mu \mathrm{s}$, of the $12.5-\mathrm{kHz}$ repetition frequency at which the TUD radar was operated; therefore every second waveform was captured, giving an effective repetition frequency of $6.25 \mathrm{kHz}$. At this rate, and when adding 512 waveforms before dumping the data to the computer, the DAS could have been read at a rate up to 12.2 times per second. The actual rate was about 8 times per second. The difference is due to the fact that the average time required for the computer to read, process, display, and write-to-tape slightly exceeded the time it took for the DAS to make data available; thus the DAS sometimes had to wait for short periods for the computer 
to finish its tasks. Most of this excess time was probably involved in the PGC graphics operations. The transfer of data from the DAS to the computer took approximately $12 \mathrm{~ms}$ and the write-to-tape was executed asynchronously, requiring only a few ms to initiate. Five records were accumulated in the tape drive buffer before being written to tape. The actual "write" took about $200 \mathrm{~ms}$ to complete. It may be noted that the PC/AT was running at an $8-\mathrm{MHz}$ clock rate, and the software was written entirely in assembly language for maximum speed.

Fig. 5 is a black-and-white photograph of the color CRT screen as it appeared on the part of a N-S line that went over the base camp. Two metal aircraft cargo pallets, measuring slightly more than $2 \mathrm{~m}$ on a side, had been set up on edge and provided an excellent radar reflector that produced the diagonal stripe (marked by the diagonal arrow). The fact that the reflection from the cargo pallets can be detected several kilometers away from camp is largely due to the wide, $120^{\circ}, 3-\mathrm{dB}$ beamwidth alongtrack of the antenna system, which consists of four broadband dipoles mounted $1 / 4$ of a wavelength below the wing [1]. The 3-dB beamwidth side-to-side is $20^{\circ}$. At 60 $\mathrm{MHz}$, the wavelength in air is $5 \mathrm{~m}$, so the length of the edges of the cargo pallets was nearly $1 / 2$ of a wavelength, or approximately a resonant length. At the frequencies that must be used to penetrate the deepest parts of the Greenland ice sheet, it is impractical to produce narrow beamwidths using physical arrays of many elements because the size would be too large. The tip of the arrow near the top of the figure is at the top of the lower of two bright horizontal bands and corresponds to the location of the return from the ice surface. The two bands are caused by receiver saturation (see also Fig. 4). The top saturation band is a residual effect from the transmitter pulse and is present just after the receiver is turned on. The thin dark band between the two bright bands indicates recovery from saturation. The second bright band is due to saturation caused by the strong return from the ice surface. The saturation is the reason that the diagonal return from the pallets does not persist to the surface. The tip of the top arrow also indicates the base camp location. The flight altitude above the ice was typically 150 to $300 \mathrm{~m}$. The flight lines were flown at a constant pressure altitude so the height above the ice varied for different locations on the grid.

The navigation data are synchronized with the magnetic tape radar data so that precise locations will be available on all of the lines when they are fully processed, but the return from the pallets and the time calibration marker, visible along the left-hand edge of the figure, provide an alternative means of approximately calibrating the horizontal dimension of Fig. 5. The marks on the time calibration are at $2 \mu$ s intervals. Since the pallet reflection was propagating in air, the propagation velocity was $3 \times$ $10^{8} \mathrm{~m} / \mathrm{s}$, and the total width of Fig. 5 represents approximately $5.8 \mathrm{~km}$.

The return from bedrock is indicated by the vertical arrow near the bottom of Fig. 5. Again using the time cal-

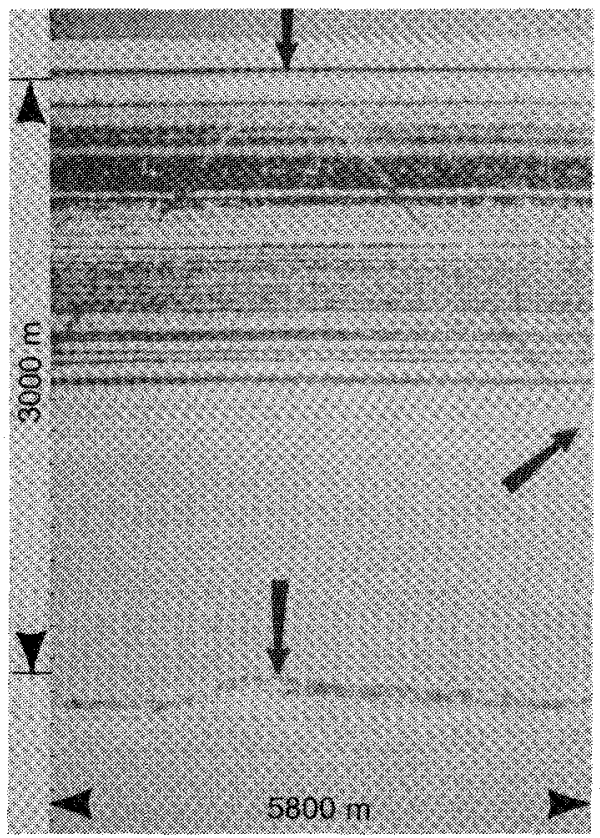

Fig. 5. During profiling the display was a rasterized color scale. The blackand-white reproductions here lose some detail. This figure shows a segment of a NS line through the centerline of the grid. The top arrow locates the surface return and also the location of the base camp set up at the center of the grid. The diagonal arrow indicates the reflection from metal aircraft cargo pallets. The bottom arrow indicates the bottom reflection. Note that the bottom is not completely flat in this location.

ibration and assuming an average velocity in the ice of $1.67 \times 10^{8} \mathrm{~m} / \mathrm{s}$, the thickness of ice at the base camp is calculated to be $3000 \mathrm{~m}$. It should be noted that errors exist in the measurements because of the curvature in the CRT screen. More accurate measurements will be made as part of the full data-reduction process.

The horizontal stripes below the receiver saturation bands are a common feature of radar sounding of polar ice sheets. This "internal layering" is postulated to be due to slight increases in the acidity, and hence the electrical conductivity, of the ice during periods of increased volcanic activity in the northern hemisphere [7]. The reflections are particularly dense in the top half, and faint or nonexistent in the lower half. It is not clear whether this is due to a real change in the electrical properties of the ice at this point in the geologic past (approximately 10-20 thousand years ago), or due to instrumental dynamic range limitations. This warrants further investigation.

Fig. 6 shows an example of relatively flat bottom topography taken from a north-south line $12.5-\mathrm{km}$ west of the center of the grid. In general, the topography is flatter on the western part of the grid. Note that internal layers are not visible deep in the ice.

In contrast to the previous example, Fig. 7 shows an extremely mountainous segment. Note that in this case internal layers are visible quite deep in the ice and that these layers drape over the topography. Fig. 7 is part of a north-south line flown along the mountainous eastern boundary of the grid. 


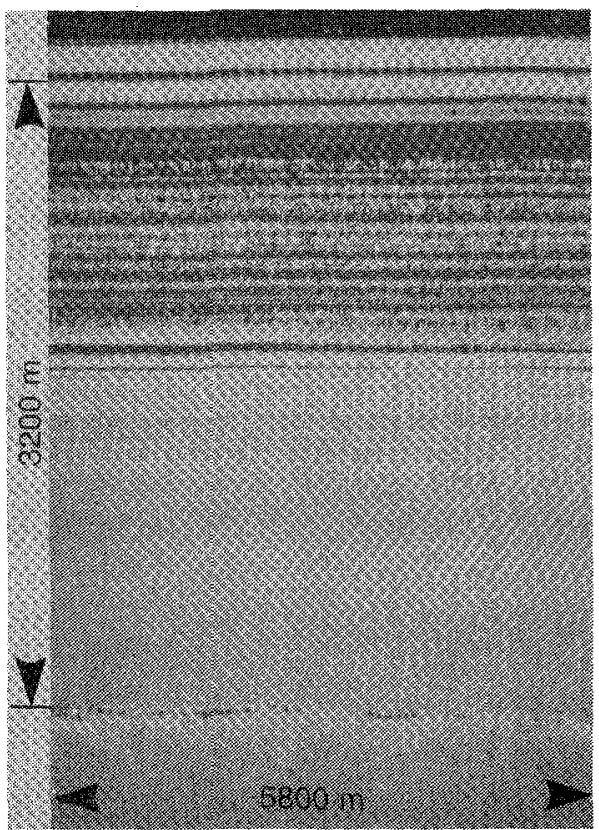

Fig. 6. This segment is part of a NS line $12.5-\mathrm{km}$ west of the centerline of the grid. Note the relatively flat topography. Any internal layers deep in the ice are not visible in this region.

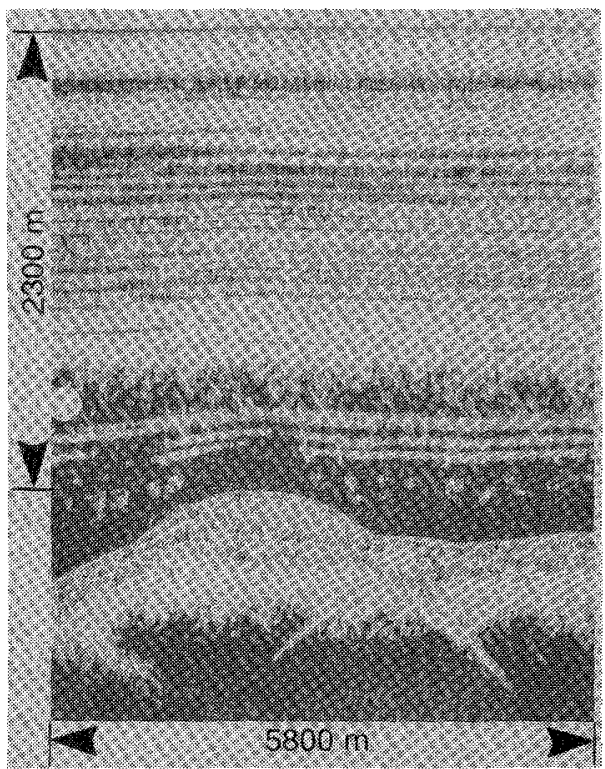

Fig. 7. This segment is part of a NS line flown along the mountainous eastern boundary of the grid. Note that quite deep in the ice internal layering is visible and that this layering follows the bottom topography. The dot at the left-hand side locates a zone where strong cross-hatching is visible in the data. This is thought to be due to reflections from surface roughness or crevasses. The slopes of the cross hatching appear to be the same as the slope of the return from the cargo pallets in Fig. 5, as they should be for surface-generated features.

\section{Conclusions, Other Applications, and POSSIBLE IMPROVEMENTS}

The new data acquisition system, including very highspeed signal addition, is able to record airborne icesounding radar data with excellent spatial density ( 10 to 20 -m spacing at $\mathrm{LC}-130$ speeds in ice 3000 -m thick) while simultaneously providing 512 waveform additions for a useful signal-to-noise improvement. The signal-to-noise improvement is $13 \mathrm{~dB}$ for uncorrelated noise and a squarelaw-detected received signal (no phase information). The theoretical improvement would be $27 \mathrm{~dB}$ for a coherent (phase preserving) waveform addition provided that the phases of the received waveforms remained consistent over the 10 to $20-\mathrm{m}$ spatial averaging window. The system was reliable in the field, and no problems were encountered after an interface cable was replaced.

Over 6000 -line $\mathrm{km}$ of ice-sounding radar data over the Greenland ice sheet with good navigational control were recorded on 9-track computer tape. Maps produced from these data will provide the best topographical information to date of the part of the Greenland ice sheet that was flown, and will prove to be invaluable in siting the scientific corehole through the Greenland ice sheet.

Surface and borehole applications of the new DAS will allow more signal addition and therefore increased signalto-noise enhancement. The system is sufficiently flexible to be used with a number of high repetition rate geophysical radars, as evidenced by the fact that the system was initially designed with no thought of using it with the TUD radar system. It is possible that the system may have potential applications to signal enhancement in other types of active probing such as ultrasonic scanning or in any application in which 1 to $100-\mathrm{MHz}$ signal frequencies and 1 to $50-\mathrm{kHz}$ repetition rates are encountered. Use of a higher frequency digitizer or sampling could remove the $100-\mathrm{MHz}$ upper limit on the signal frequency. Faster SRAM chips and revised architecture could allow the construction of a system that would add signals as fast as the signals could be digitized. If this were done, the only limit on the signal repetition rate would be the limit set by the duration of the digitizing window and/or, depending on the number of waveforms added, data transfer, processing, and display times.

\section{ACKNOWLEDGMENT}

The authors thank the Antarctic Development Squadron Six (VXE-6) of the U.S. Navy for making it possible to complete the required ice sounding in a limited time by their safe and efficient operation of the LC-130 aircraft. We also thank N. Skou and E. Lintz Christensen of the Technical University of Denmark for installation and reliable operation of the TUD radar system.

This work was partially supported by the National Science Foundation under Agreement No. DPP-8518618. Any opinions, findings, and conclusions or recommendations expressed herein are those of the authors and do not necessarily reflect those of the National Science Foundation. Brand names are used for technical aspects only and do not imply endorsement by the U.S. Geological Survey or the National Science Foundation.

\section{REFERENCES}

[1] N. Skou and F. Sondergaard, "Radioglaciology: A $60 \mathrm{MHz}$ ice sounder system," Electromagnetics Instit., Tech. Univ. of Denmark, Lyngby, Rep. R 169, 1976. 
[2] "FY 1988 geosciences program," Directorate for Geosciences and Directorate for Biological and Social Sciences, Nat. Sci. Found., Washington, DC, 1987.

[3] J. A. Bradley and D. L. Wright, "Microprocessor-based data-acquisition system for a borehole radar," IEEE Trans. Geosci. Remote Sensing, vol. GE-25, pp. 441-447, 1987.

[4] D. L. Wright and R. D. Watts, "A single-hole, short-pulse radar system," in Proc. Nucl. Energy Agency, Orgz. for Econ. Co-operation and Devel. Workshop on Geophys. Invest. in Connection with Nucl. Waste (Ottawa, ON, Can.), Sept. 8-10, 1982, pp. 267-279.

[5] H. Terry and L. E. Radke, "A new data acquisition and display system for airborne research in Antarctica," Antarctic. J. U. S., vol. 21, no. 3, pp. 19-20, 1986.

[6] R. D. Watts and D. L. Wright, "Systems for measuring thickness of temperate and polar ice from the ground or from the air," J. Glaciol., vol. 27 , no. 97, pp. 459-469, 1981.

[7] S. M. Hodge, "Ice sheet topography and internal characteristics from microwave and radar measurements," paper presented at the 19th Int. Symp, on Remote Sensing of the Environ., Ann Arbor, MI, Oct. 2125,1985 .

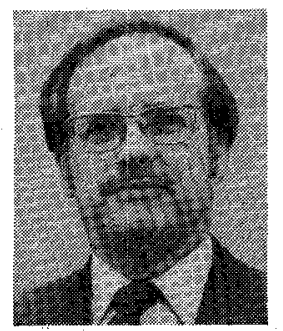

David L. Wright (S'69-M'69) received the B.S. degree in physics from Wheaton College, Wheaton, IL, in 1962, the M.S. degree in physics from the University of Illinois, Urbana, in 1963, and the $\mathrm{Ph} . \mathrm{D}$. degree in electrical engineering from the University of New Mexico, Albuquerque, in 1970.

He was with EG\&G, Inc. and the Dikewood Corporation in Albuquerque, NM. In 1973 he joined the Department of Electrical Engineering, Colorado State University, Fort Collins. He joined the U.S. Geological Survey in 1978, where he is engaged in research and development of high-frequency electromagnetic techniques for geophysical measurements, including borehole, surface, and airborne radar systems. He has also been engaged in research on antennas in a reentry environment, laser heating of plasmas, and nuclear electromagnetic pulse simulation.

Dr. Wright has served as Chairman of the Denver-Boulder Joint Chapter of the Antennas and Propagation, Microwave Theory and Techniques, and Geoscience and Remote Sensing Societies of the IEEE, and is a member of the Society of Exploration Geophysicists and Sigma Pi Sigma.

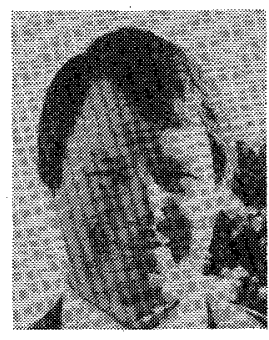

Jerry A. Bradley graduated from Highland High School, Albuquerque, NM, in 1958.

In 1962 he joined the U.S. Army, where he spent one year at the U.S. Army Signal School, Fort Monmouth, NJ. From 1965 to 1968 he worked for Texas Instruments and EG\&G, Inc. as a Senior Technician, where he assisted in the development of new test instrumentation. In 1968 he joined the Incre Data Corporation in Albuquerque, where he helped develop a small data acquisition system which was the first such instrument to record on computer-compatible tape. In 1974 he joined the U.S. Geological Survey, Branch of Geophysics, where currently he is responsible for the development of specialized data acquisition systems and computer interfaces for the collection and storage of geophysical field data. He has designed data acquisition systems for borehole and ice-sounding radar systems and participated in airborne and surface radar ice-sounding studies in Greenland and Antarctica.

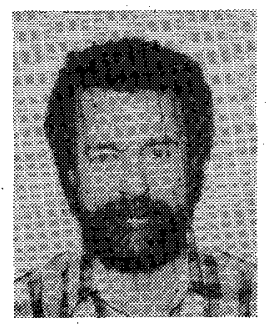

Steven M. Hodge received the B.Sc. degree in physics from the University of British Columbia, Vancouver, in 1964, did additional study at the University of California, Berkeley, and received the $\mathrm{Ph}$.D. degree in geophysics from the University of Washington, Seattle, in 1972.

He joined the U.S. Geological Survey, Water Resources Division, in 1972, where he specializes in glaciology. Much of his research has been concerned with the relationship of basal water pressure to the basal sliding of glaciers. He has applied finite element flow models to glaciers and ice sheets and has analyzed polar ice sheets using satellite radar data. Since the day it was first demonstrated that temperate ice could be sounded by using a low enough frequency short-pulse radar, he has been active in the development of such systems and has used them at locations from Alaska to Antarctica:

Dr. Hodge has served on the Snow and Ice Committee, American Geophysical Union, and on the Committee on Glaciology, Polar Research Board, National Academy of Sciences, and as the USGS Research Advisor for Snow and Ice. He is a member of the American Geophysical Union and the International Glaciological Society. 